\title{
A IMUNIDADE TRIBUTÁRIA DO SERVIÇO PÚBLICO
}

\author{
PROF. PAULO ALBERTO PASQUALINI *
}

SERVIÇO PÚBLICO: noção e caracteres; tipos de serviço público. Serviço de assistência. As Caixas Econômicas realizam um serviço de assistência à pequena economia privada. Garantias concedidas pela ordem jurídica ao serviço público. Imunidade tributária. Autarquias como forma de descentralização dos serviços públicos. Sua imunidade tributária. As Caixas Econômicas Estaduais são entidades autárquicas que executam um serviço público, gozando, por conseguinte, de imunidade tributária. As Caixas Econômicas desenvolvem a sua atividade em parte dentro do Direito Privado. Os atos praticados por elas, no exercício de um serviço público, embora no plano do direito privado, são imunes à incidência de qualquer tributo, sendo inadmissível a criação, nesse caso, da figura do substitutc legal tributário.

1 - Para conceituar o que é serviço público é necessário estabelecer uma distinção prévia entre interêsse individual e interêsse coletivo ou público. $O$ interêsse individual se manifesta na tendência que os homens demonstram com relação a bens do mundo exterior, capazes de dar satisfação às suas necessidades. Deve-se considerar, entretanto, que o indivíduo não vive isolado e não poderia com a sua simples atividade dar satisfação a tôdas as suas necessidades. A vida humana é eminentemente social e se desenvolve sempre no sentido da cooperação e da união de esforços em

* Professor de Direito Administrativo. 
vista de fins comuns. A vida em sociedade apresenta múltiplas relações e as suas necessidades dão lugar a diversos tipos de coesão social. Assim, ao lado dos interêsses individuais, próprios dos indivíduos, nós encontramos ainda interêsses coletivos, peculiares ao todo social. Ditos interêsses coletivos não resultam da soma dos interêsses particulares, mas derivam das necessidades da vida em comum. Certo, não é possivel estabelecer uma distinção absoluta entre interêsses individuais e interêsses gerais, mas, por outro lado, é possível se falar em interêsses prevalentemente individuais em contraposição a interêsses prevalentemente públicos.

Para os primeiros, o indivíduo é colocado no primeiro plano e só indiretamente se o considera como componente de um grupo social; para os segundos a consideração é estabelecida em sentido oposto, sendo, o indivíduo, observado enquanto parte de um todo social.

2 - Os fins coletivos reclamam a união dos homens. Não podem os objetivos comuns ser atingidos a não ser pelo esfôrço comum através de uma soma de energias. Entre as formas de coesão social aquela que prepondera é sem dúvida a do Estado, manifestação suprema da aglutinação de uma sociedade. E no Estado que a organização da sociedade adquire uma dimensão mais ampla, pois é nele que ela encontra o seu centro. O Estado representa a fonte primeira da ordem jurídica, pois é de sua atividade que se origina a lei e é ainda através de sua ação que a ordem jurídica é mantida e asseguradas a paz e a tranqüilidade públicas. O Estado vive, assim, permanentemente, um processo lento mas constante, de ampliação de suas atividades e de absorção de tarefas que não lhe pertenciam até bem pouco tempo. O Estado moderno está dotado, destarte, de poderosíssimos meios, tanto jurídicos como econômicos, e se utiliza dêsses instrumentos no sentido de dar uma satisfação plena àquelas exigências fundamentais que são postas pela sociedade. O Estado tem assumido, portanto, encargos que não lhe eram outrora atribuidos e além disso, procura suprir e integrar a esfera de livre atividade do individuo (GEORG JELLINEK ALLGEMEINE STAATSLEHRE, ed. 1905, p. 254). O poder do Estado é incontrastável dentro de seu território. Possui êle os meios para submeter à sua vontade própria todos os indivíduos e tôdas as pessoas jurídicas que lhe estejam submetidas.

3 - O Estado, entretanto, no desenvolvimento de sua ação, está vinculado a fins que não podem ser desconhecidos pelo arbítrio dos governantes (RUY CIRNE LIMA, PRINCÍPIOS DE DIREITO ADMINISTRATIVO BRASILEIRO, ed. 1954, p. 53). Esses fins transcendem os limites do interêsse particular dos indi- víduos para se situarem no plano mais elevado do interêsse e da utilidade públicas. Os fins públicos, porém, não podem ser estabelecidos tendo como base critérios objetivos, mas decorrem de uma opção que, num momento histórico, é feita pelo Estado. E verdade que essa escolha não é realizada em têrmos de vontade indeterminada, mas decorre das peculiares condições sociais, políticas e econômicas do momento (RUY CIRNE LIMA, ob. citada, p. 16). O Estado, diante dessas condições, faz uma opção e assume e reconhece alguns dos fins propostos como próprios e passa a desenvolver a sua ação no sentido de sua conservação e realização plena.

O conceito de fim público e de interêsse público é, por conseguinte, variável, pois a esfera de atribuições do Estado é mutável nos diversos momentos históricos, com uma tendência constante no sentido de um alargamento diante das atividades dos indivíduos e das organizações privadas.

4 - Ora, o primeiro critério para discernir o serviço público das outras formas de atividade com as quais possa apresentar pontos de contato e de semelhança está na finalidade para qual êle tende, que é eminentemente pública. O Estado é que reconhece, em determinado momento, uma atividade como necessária à satisfa. ção de interêsses públicos. Nesta escolha a sua vontade é soberana e se manifesta no momento em que êle assume direta ou indiretamente o encargo de prestar o serviço ou de assegurar a sua prestação à sociedade. Porque há uma finalidade pública a ser atendida são organizados os instrumentos de ação que irão dar satisfação ao interêsse coletivo.

5 - Tão importante é a noção de serviço público que o grande publicista francês LEON DUGUIT sustenta que "os servicos públicos são um dos elementos do Estado" e que "o Estado não é, como o quiseram fazer e como se acreditou durante algum tempo que êle era, um poder que comanda, uma entidade soberana; êle é uma cooperacão de servicos públicos organizados e controlados pelos governantes" (TRAITÉ DE DROIT CONSTITUTIONNEL, t. II, p.59, ed. 1928).

6 - O serviço público é, assim, uma atividade, cuja realização deve ser assegurada, regulada e controlada pelo Estado, porque o desdobramento dessa atividade é "indispensável à concretização e ao desenvolvimento da interdependência social e é de tal natureza que não pode ser desenvolvida completamente a não ser pela intervenção da fôrça governante." (LEON DUGUIT ob. cit., p.61). 
7 - O Estado é o único juiz das exigências que decorrem do interêsse geral e aprecia livremente se, em um dado momento, a satisfação de uma necessidade de interêsse geral deve dar lugar à criação de um serviço público. É só ao poder público que pertence a decisão no tocante à elevação de uma atividade à condição de serviço público (ANDRÉ DE LAUBADERE, TRAITÉ ÉLÉMENTAIRE DE DROIT ADMINISTRATIF, t. I, p.520. ed. 1963).

$\mathrm{O}$ critério dos serviços públicos decorre da intenção dos governantes, que são os juízes da questão. $\mathrm{O}$ domínio do serviço público é, por conseguinte, contingente.

8 - Aquilo que foi dito leva a que se afaste a tese de que se pode enunciar em têrmos objetivos um domínio natural dentro do qual se exerce o serviço público. Não há um serviço público por natureza, pois o âmbito do serviço público é variável de acôrdo com as épocas e as concepções dominantes no poder. A concepção dominante é a de que o conceito de serviço público é um dado que pressupõe circunstâncias de natureza histórica e social, que são, por conseguinte, essencialmente variáveis e não se prestam a uma fixação conceitual em têrmos lógico-jurídicos. É por isso que as definições de serviço público não tentam determinar de modo estático o seu conceito, mas levam em consideração aquêle aspecto de fluidez e de indeterminação que se manifesta no serviço público. Serviço público é, assim, denominado "todo o serviço existencial, relativamente à sociedade ou, pelo menos, assim havido em um momento dado, que, por isso mesmo, tem de ser prestado aos componentes daquela, direta ou indiretamente, pelo Estado ou outra pessoa administrativa" (RUY CIRNE LIMA, PRINCIPIOS DE DIREITO ADMINISTRATIVO BRASILEIRO, ed. 1954, p. 84).

9 - O Estado tem o dever de organizar e de por em funcionamento os serviços públicos. GASTON JEZE ressalta êsse dever e a sua enunciação implícita feita no preâmbulo da Constituição Americana, no qual essa se diz adotada, "in order to... esta blishjustice, insure domestic tranquillity, provide for the common defense, promote the general welfare, and secure the blessings of liberty to ourselves and our posterity" (LES PRINCIPES GENERAUX DU DROIT ADMINISTRATIF, t. III, p. 6, 1926).

10 - São várias as espécies de serviço público. "Pode-se dizer que, à medida que a civilização se desenvolve, o número das atividades suscetíveis de servir de base para serviços públicos aumenta e o número dos serviços públicos é acrescido por isso mesmo. E lógico. Com efeito, da civilização se pode dizer que ela consiste ùnicamente no crescimento constante do número de necessidades de tôda a ordem podendo ser satisfeitas em um tempo menor. À medida em que a civilização progride, a intervenção dos governantes torna-se normal e mais freqüente porque só ela pode realizar aquilo em que consiste a civilização" (LEON DUGUIT, ob. cit. p. 63 ).

11 - Dentre os tipos de serviço público, é indúbito, deve ser enunciado o serviço de assistência. É certo que o serviço de assistência, na medida em que é assegurado pelo Estado, se constitu num autêntico servico público (LEON DUGUIT, ob. cit. p. 63). Inegável é, também, que as Caixas Econômicas desempenham uma atividade assistencial, pois elas executam o serviço de assistência à pequena economia privada (RUY CIRNE LIMA, ob. cit., p.71) Não importa que a atividade assistencial esteja repartida entre o Estado e os particulares, pois o caráter de serviço público de uma atividade não implica em monopólio em proveito do Estado (LEON DUGUIT, ob. citada, p.63). As Caixas Econômicas, de resto, são, de longa data, reconhecidas como instituições que atuam naquêle setor a que a Constituição do Império, art. 179, § 31, denominava de "sacorros públicos". Segundo PEREIRA DO REGO a expressão socorros públicos designava "o complexo dos serviços organizados para socorrer a indigência" (ELEMENTOS DE DIREITO ADMINISTRATIVO BRASILEIRO, 1860, p.249, § 317). Dentre êsses serviços estavam colocadas as Caixas Econômicas, que, segundo o mesmo autor, "são estabelecimentos filantrópicos cujo objeto é receber em depósito as pequenas somas que lhe são confiadas, vencendo juros, e ajudar assim as pessoas laboriosas a fazer economias (ob. cit. p. 250, § 319). Nenhuma dúvida há, por conseguinte, desde a época imperial, com relação à função assistencial exercitada pelas Caixas Econômicas, pois "ajudar o obreiro ou o proletário a criar um capital é o serviço mais eminente que se pode prestar a essa classe numerosa e importante da sociedade" (Pereira do Rêgo ob. cit. p.250, § 319).

12 - A medida da importância dos serviços públicos nos é dada pelas garantias de que êles gozam. O patriotismo dos agentes e o não predomínio do intuito de lucro são garantias que protegem o serviço contra os seus próprios agentes. A continuação da prestação do serviço em caso de penhora ou no de falência da emprêsa concessionária visam assegurar e proteger o serviço contra os interêsses de natureza privada suscetíveis de prejudicarem a sua execução regular e continuada. Vem, finalmente, a garantia da imunidade tributária para proteger o serviço público e resguardar a sua integridade contra os interêsses fiscais das demais pes- 
soas administrativas, capazes de, por essa via, criarem-lhe embaraços e encargos (RUY CIRNE LIMA, PRINCÍPIOS, 1954, p.85) Tamanhas garantias, contra os agentes, contra os particulares em geral e contra as próprias pessoas administrativas estão a mostrar que tais serviços são, realmente, reputados existenciais relativamente à sociedades; não se compreenderia tamanho rigor de direito para assegurar-se a só conveniência, confôrto ou recreio dos indivíduos ou da coletividade (RUY CIRNE LIMA, ob. cit. ibidem).

13 - A garantia da imunidade tributária é, sem dúvida, a mais importante das garantias de que desfruta o serviço público.

Reside, ela, na proibição constante do art. 19, inciso III, letra a), da Constituição Federal, que veda à União, aos Estados, ao Distrito Federal e aos Municípios instituir impôsto sôbre o patrimônio, a renda ou os serviços uns dos outros. A regra jurídica de imunidade é norma que se estabelece no plano das normas de competência dos podêres públicos, que obsta totalmente a atividade legislativa no sentido da criação de impostos. "Nos Estados em que a Constituição é rígida, como o Brasil, a imunidade é limitacão constitucional à competência para edictar regras jurídicas de imposição" (PONTES DE MIRANDA, COMENTÃRIOS À CONS TITUIÇÃO DE 1967, com a emenda $n^{\circ} 1$ de 1969, t. I, p.408, ed. 1970). A regra jurídica do art. 19, III, a, da C. F. de 1967, é evidentemente uma disposição que estabelece imunidade tributária e não simples isenção. Trata-se de imunidade tributária porque a mencionada norma traduz uma vedação, imposta ao Poder Legislativo, no sentido de tolher em seu nascedouro qualquer tentativa de imposição sôbre os serviços públicos.

14 - Os impostos e os demais tributos ou recaem sôbre as pessoas, ou sôbre os bens. Ali a imposição é subjetiva; aqui, objetiva (PONTES DE MIRANDA, ob. cit. p.409). Há por consequiência, uma distinção já tradicional na doutrina, entre impostos subjetivos e objetivos. Os primeros voltam-se diretamente para a pessoa do contribuinte, cuja riqueza patrimonial serve para deter minar o montante do tributo. Os segundos, ao contrário, incidem sôbre um determinado rendimento, ou um grupo de rendimentos, independentemente das condições pessoais do sujeito passivo (A.D. GIANNINI - I CONCETTI FONDAMENTALI DEL DIRITTO TRIBUTÁRIO, ed. — UTET, 1956, p.90). No que diz respeito à imunidade tributária, quando a vedação constitucional de imposição diz respeito a um impôsto subjetivo, a imunidade é subjetiva; quando se refere a um impôsto objetivo, a imunidade é objetiva.
15 - As limitações jurídicas ao poder financeiro originário, decorrente das direito interno, aparecem nos Estados Federais tanto para a União quanto para os Estados membros (A.D. GIANNINI - I CONCETTI FONDAMENTALI DEL DIRITTO TRIBUTARIO, p.232, letra b) ). São normas que são fixadas no plano superior ao da legislação ordinária em têrmos constitucionais, porque a imunidade tributária é matéria constitucional. Não importa existam regras de isenção anteriores à regra constitucional de imunidade. Se a regra jurídica de isenção precedeu à de imunidade, sendo da mesma extensão, a regra jurídica, que era de isenção, se transforma em regra jurídica de imunidade. Se a regra de isenção precedente era de menor extensão, ela é abrogada pela regra constitucional que imuniza mais pessoas ou bens do que aquêles que estavam isentos de acôrdo com a regra de isenção (PONTES DE MIRANDA ob. cit., p.408). Assim, a regra de isenção, estabelecida pelo art. $9^{\circ}$, III, letra a), da Lei 5.172 , de 25 10.1966, que definiu o Sistema Tributário Nacional, regra essa que confere isenção aos serviços públicos, deve ser considerada como regra de imunidade por fôrça da disposição constitucional da C.F. de 1967.

16 - A imunidade tributária do serviço público é objetiva ou subjetiva? A questão suscitada não apresenta uma única resposta. O serviço público, como individualidade jurídica, é uma figura indecisa em seus caracteres, pois ora denota os sinais predominantes da individualidade pessoa, ora a predominância dos da individualidade coisa. Assim, há serviços que são autônomos e se mostram, entretanto, distituidos de personalidade jurídica. São serviços que têm apenas autonomia funcional. Por outro lado, há, também, serviços públicos que são havidos como coisa, sem que, contudo, verdadeiramente o sejam. Estão nesse caso os serviços em favor dos quais se estabelecem servidões administrativas, pois lhes cabe papel análogo ao da "res dominans" da servidão de direito privado (RUY CIRNE LIMA, PRINCIPIOS, 1964, p. 81). A imunidade do servico público pode, assim, ser justificada tanto como imunidade subjetiva, se o serviço público fôr dotado de personalidade jurídica, ou como objetiva, se o serviço fôr constituído em têrmos de autonomia funcional sem personalidade jurídica. Por conseguinte, o serviço público está protegido por ambos os conceitos de imunidade. Se nêle preponderar o aspecto de coisa, de atividade material, a imunidade objetiva o portegerá. Se a personalidade jurídica fôr o seu traço fundamental, tocará à imunidade subjetiva a sua proteção. 
17 - Os serviços públicos, por conseguinte, não podem ser tributados. Os serviços públicos desenvolvem a sua atuação no setor que E. FORSTHOFF denomina de "assistência vital". "Tôdas as prestações oferecidas pela Administração aos cidadãos são formas da assistência vital. Não é preciso distinguir se essas prestações são vitalmente necessárias ou não." O homem moderno está vinculado em tão elevada medida a determinadas prestações como a água, a eletricidade, o gás e os meios de transporte, que não tem margem mais para escolher se quer aceitá-las ou não, enquanto que usa o seu arbítrio para ir até o teatro ..." (ERNST FORSTHOFF, TRATADO DE DERECHO ADMINISTRATIVO, ed. 1958, p.476). Assim, tôda a assistência vital pública é, nesse sentido, Administração Pública, independentemente das formas por que se exerça. $O$ conceito de serviço público permite que se leve a efeito uma unificação das diversas prestações da administração pública, colocando lado a lado a atividade estatal soberana com a atividade assistencial, inclusive aquela que tem raízes no setor econômico e financeiro.

18 - A descentralização administrativa encontra um dos momentos de sua concretização no serviço público. À descentralização por serviços são devidos os estabelecimentos públicos, que são serviços públicos personalizados (RUY CIRNE LIMA, ob. cit. ed. 1964, p.150). Mediante a descentralização administrativa são criadas entidades autárquicas, na forma de estabelecimentos públicos, que, como já dissemos, encontram no serviço público a base para a sua personificação. "Dá-se a descentralização de atividade administrativa por pessoa pública quando o Estado cria, ao lado da sua, outras capacidades de direito público, para assumirem como próprias as funções ou serviços que lhes foram conferidas. Atribui às pessoas que criou não apenas o exercício de uma atividade que lhe competiria, mas outorga-lhes a titularidade sôbre ela. Por isso a pessoa em questão terá negócios próprios, interêsses próprios, que são negócios e interêsses públicos" (CELSO ANTONIO BANDEIRA DE MELLO, NATUREZA E REGIME JURIDICO DAS AUTARQUIAS, 1968, p.90).

19 - Os estabelecimentos públicos representam uma das três formas estruturais que podem assumir as entidades autárquicas. $\mathrm{O}$ estabelecimento público é o serviço público a que se reconhece personalidade jurídica. Não é uma corporação por isso que lhe faltam membros ou associados. Não é, também, uma fundação por que a sua personificação não se explica pelo mero propósito de dar destino a um patrimônio (RUY CIRNE LIMA, PRINCÍPIOS, ed. 1954 p.67). Da França nos vem a lição de que o "estabelecimento pú- blico é ... um modo de gestão dos serviços públicos, como um serviço público dotado de personalidade jurídica" (ANDRE DE LAUBADÈRE, ob. citada, p.160). Os estabelecimenots públicos são pessoas jurídicas criadas pelo Estado através da via legislativa. A sua organização, a sua direção e o seu funcionamento decorrem das disposições legais que autorizaram a sua instituição. Os fins a que se destina o estabelecimento público são fins de administracão pública, como tal vinculados à relação de administração (RUY CIRNE LIMA，PRINCÍPIOS, ed. 1954, p.65; FRITZ FEINER, INSTITUCIONES DE DERECHO ADMINISTRATIVO 1933, p. 260; ERNST FORSTHOFF, TRATADO DE DERECHO ADMINISTRATIVO, p.633). E por isso que OTTO MAYER define o estabelecimento público como "um conjunto de meios materiais e pessoais, elevado à condição de pessoa jurídica de direitos público, que está destinado a servir permanentemente a determinado fim público, em mãos de um sujeito da administração pública" ( LE DROIT ADMINISTRATIF ALLEMAND, t. IV, p.184 e 267)

20 - As Caixas Econômicas, de iniciativa governamental, são havidas como estabelecimentos públicos, na Alemanha (E. FORS. THOFF, ob. cit., p.638; FRITZ FLEINER, ob. cit. p.261), na França (M. HAURIOU, PRECIS ÉLÉMENTAIRE DE DROIT ADMINISTRATIF, ed. 1921, p.309) e no Brasil (RUY CIRNE LIMA, ob. cit. ed. 1954, p71). Presentemente, no Brasil, apenas as Caixas Econômicas Estaduais correspondem à figura do estabelecimento público, já que as Caixas Econômicas Federais foram unificadas sob a forma de emprêsa pública, com personalidade jurídica de direito privado, nos têrmos do art. $1^{\circ}$ do Decreto-Lei 759 , de 12 de agôsto de 1969.

21 - As Caixas Econômicas são o instrumento de execução de um serviço público, o serviço de assistência à pequena economia priprivada (RUY CIRNE LIMA, ob. cit. ed. 1954, p.71). As Caixas Econômicas são estabelecimentos públicos cujo funcionamento, com relação aos usuários do serviço, é disciplinado pelo Direito Privado e não pelo Direito Público. "Existem instituições", - afirma E. FORSTHOFF, "com Estatuto de utilização de Direito Público e outras com estatuto de D. Privado, pelo qual as relações jurídicas entre o usuário e o estabelecimento deverão ser examinadas seja conforme ao D. Público, seja conforme ao D. Privado", sendo, por exemplo, o pagamento que o usuário efetuar pela utilização, ou bem uma taxa que pode ser arrecadada mediante procedimento administrativo, ou uma prestação que, baseada em contrato, pode ser reclamada pela via judicial ordinária" (ob. cit. p.637). Todavia, a atividade desenvolvida pelas Caixas Econômicas, embora se 
realizando no plano do D. Privado quanto aos seus utentes, representa a manifestação do poder público com relação a um serviço cuja finalidade interessa sobremaneira ao Estado. Não importa, por conseguinte que as relações das Caixas Econômicas com os seus usuários se estabeleçam nos têrmos do Direito Civil, quando se sabe que êsse tipo de relacionamento é um pressuposto para a execução de um serviço público.

22 - As Caixas Econômicas oferecem, por conseguinte, a peculiaridade de prestarem o serviço assistencial, de que são titulares, principalmente dentro de formas privatísticas. São prestações oferecidas a particulares, que se regulam pelas regras do $\mathrm{Di}$ reito Civil. Assim, as figuras do mútuo, do depósito, das garantias reais e fiduciárias são momentos comuns no relacionamento das Caixas Econômicas com os seus usuários.

23 - Sendo, as Caixas Econômicas, estabelecimentos que se constituem como serviço público dotado de personalidade jurídica todos os atos que elas realizam, dentro dos fins prefixados pela lei como obrigatórios, porque situados no âmbito da atividade assistencial, estão protegidos por tôdas as garantias que beneficiam o serviço público.

24 - Dentre as garantias concedidas em favor dos serviços públicos se conumera a da imunidade tributária definida pela Constituição. Trata-se de uma regra constitucional que veda qualquer imposição sôbre o serviço público, já em seu nascedouro. Em se tratando de servico público essa imunidade, como já referimos, pode ser considerada tanto como imunidade subjetiva como objetiva. Imunidade subjetiva se o serviço fôr visualizado pelo aspecto da personalidade jurídica, que, inequivocamente, é o traço de muitos serviços públicos constituidos em forma de estabelecimentos públicos. Nenhum ato proveniente de um estabelecimento público poderia sofrer tributação porque a regra constitucional pré-exclui a possibilidade de edição de qualquer regra de incidência. Imunidade objetiva, se fôrem consideradas as operações, os atos jurídicos de que participarem serviços públicos, ou mesmo se o serviço público aparecer sob o aspecto de coisa, que, muitas vêzes, êle apresenta.

25 - À imunidade reconhecida pela Constituição em proveito do serviço público deve-se acrescentar aquela que diz respeito às entidades autárquicas. Com efeito, o $\S 1^{\circ}$ do art. $19 \mathrm{da}$ C.F., estende às autarquias a proteção da imunidade tributária, no que se refere ao patrimônio, à renda e aos serviços vinculados às suas finalidades essenciais.
26 - Sendo, as Caixas Econômicas Estaduais, entidades autárquicas constituidas na forma de estabelecimentos públicos, essa situação de pessoas de direito público vem se somar à prestação de um serviço público, que elas, de forma inequívoca, realizam, no sentido da reafirmação da imunidade tributária de que elas gozam. Por conseguinte, as Caixas Econômicas, quando constituídas como estabelecimentos públicos, gozam de imunidade tributária por dois motivos: a) em primeiro lugar, por prestarem um serviço público; b) em segundo lugar, por que são entidades autárquicas.

27 - As Caixas Econômicas, quando realizam um serviço público ou praticam atos que se referem ao seu patrimônio e à obtenção de rendas não podem ser atingidas por nenhuma regra tributária. Destarte, os atos jurídicos por elas praticados, e os seus respectivos instrumentos, não podem se constituir em hipótese de incidência para qualquer tributo.

28 - O impôsto sôbre Operações Financeiras foi criado pela Lei 5.143, de 20-10-1966. O mencionado impôsto incide sôbre as operações de crédito e de seguro, levadas a efeito pelas instituições financeiras (art. 1 ${ }^{\circ}$ ). Contribuinte "de jure" do impôsto é a instituição financeira (art. $4^{\circ}$ ), com tal definida pelo art. $17 \mathrm{da}$ Lei 4595 , de 31.12.1964.

29 - Ora, o artigo 17 da Lei 4.595 , ao definir as instituições financeiras, mistura as instituições públicas com as privadas A aludida disposição, além de contrariar a boa técnica legislativa, cria uma certa perplexidade para a interpretação do texto da referida lei, pois no art. 24 encontra-se uma referência expressa às Caixas Econômicas, colocada na lei precisamente com o propósito de demonstrar que as Caixas Econômicas não poderiam ser sumária e genèricamente englobadas dentro do conceito de instituições financeiras. As Caixas Econômicas, tendo como objetivo o desenvolvimento de um serviço público jamais poderiam ser classificadas de forma simplista entre as instituicõos financeiras comuns, que têm como finalidade a intermediação e a guarda de recursos financeiros.

30 - O equívoco da Lei 4.595 , ao definir no art. 17 as instituicões financeiras, consistiu precisamente em estabelecer como característicos genéricos dessas instituições aquêles traços que iden tificam os estabelecimentos privados. A disposição legal não leva em consideração que os sinais indicativos que menciona não têm aplicação integral às instituições financeiras públicas. Por conse- 
guinte, a definição do art. 17 é defeituosa e não descreve de forma perfeita a figura genérica da instituição financeira.

31 - A disposição do art. $4^{\circ}$ da Lei 5.143 era, por conseguinte, totalmente inócua com referência aos estabelecimentos financeiros públicos, máxime com relação às Caixas Econômicas, que além de serem autarquias se constituem em verdadeiro serviço público. Procurando contornar essa dificuldade insuperável foi editado o Decreto-Lei 914, de 7 de outubro de 1969, que, em seu art. $1^{\circ}$, modificou a redação do art. $4^{\circ}$, da Lei 5.143 , para dizer que os contribuintes do ISOF são os tomadores de crédito e os segurados. A nova disposição legal tinha, evidentemente, enderêço certo destinando-se a assegurar a tributação das operações de crédito realizadas com instituições públicas.

32 - A mencionada norma, todavia, não pode ser aplicada às operações em que fôrem parte estabelecimentos públicos, em es pecial as Caixas Econômicas Estaduais. As Caixas Econômicas, no desenvolvimento de sua atividade assistencial, estabelecem relacões jurídicas, de acôrdo com o direito privado, com os usuários do serviço de assistência por elas prestado. E evidente que as operações de crédito levadas a efeito com êsse propósito se constituem numa condição fundamental para a concretização do serviço público de assistência que incumbe às Caixas Econômicas. Se a tributação dêsses atos fôsse admitida, a conseqüência seria a de admitir a imposição fiscal sôbre os atos relativos à execução de um serviço público. Nesse particular, não pode haver qualquer distinção, pois todos os atos praticados pelas Caixas Econômicas, dentro dos limites de suas finalidades, são atos que traduzem o exercício de um serviço público. Como não se trata de serviço público concedido, que só êsses não estão protegidos pela imunidade tributária (art. $19, \S 1^{\circ}$ C.F.), nenhum ato jurídico realizado dentro do quadro da prestação de um serviço público, mediante gestão direta ou autárquica, pode ser objeto de incidência tributária.

33 - Eor êsse motivo que o entendimento corrante da doutrina e da jurisprudência é no sentido de que a imunidade tributária afasta "ab origine" qualquer possibilidade de tributação nos atos de que participem as pessoas de direito público. $\mathrm{O}$ recurso à substituição legal do sujeito passivo do tributo, pretendido pelo $\mathrm{D}$. L. $n^{0}$ 914, não é admissível no caso das Caixas Econômicas, devido à imunidade tributária. Em acórdão do Tribunal de Alçada de São Paulo, o Des. Hely Lopes Meirelles fixou admiràvelmente a questão: "A substituição legal do sujeito passivo do tributo só é possível nos casos de isenção, nunca, porém, nos de imunidade. Não há confundir imunidade com isenção; na isenção há incidência, seguida da dispensa do pagamento do tributo; na imunidade não há incidência, o que torna inexigível o tributo de quem quer que seja, pela evidente razão de que não se pode exigir de ninguém o cumprimento de obrigação tributária inexistente. $\mathrm{Na}$ isenção pode o fisco deslocar a obrigação tributária do contribuinte isento para outro interessado não isento; na imunidade essa deslocação é jurìdicamente impossível "(REVISTA DE DIREITO ADMINISTRATIVO, vol. 84, p.142).

34 - Nem outra poderia ser a posição da jurisprudência, pois a admissão da transferência do encargo fiscal para outra parte, no caso da imunidade estabelecida pela Constituição, representaria uma forma disfarçada de tributar o serviço público ou a entidade autárquica, que é precisamente o que a norma constitucional deseja evitar. A imunidade tributária do serviço público e das entidades autárquicas que executam serviço público abrange, por conseguinte, todos os atos praticados dentro dos propósitos de prestação do serviço aos usuários. Nenhum dêsses atos poderia servir como hipótese de incidência para o lançamento de qualquer tributo. A norma legal que assim dispuser estará violentando a Lel Maior e, como tal, será inconstitucional.

35 - Os atos jurídicos praticados pelas Caixas Econômicas Estaduais, no cumprimento de seus deveres relacionados com a execução do serviço de assistência à pequena economia privada, são imunes à incidência de qualquer tributo. Por conseguinte, a regra do art. $1^{\circ}$, do Decreto-Lei 914 , de 7-10-1969, que altera a figura do contribuinte "de jure" do Impôsto sôbre Operações Financeiras, não se aplica aos atos jurídicos de que elas praticiparem. 